\title{
Aeroelastic Stability Analysis of Compressor Blades in High-low Altitude
}

\author{
Xiang Zhang ${ }^{1, a}$, Yuchun Chen ${ }^{1, b}$, Xiuquan Huang ${ }^{1, c}$ \\ ${ }^{1}$ NorthWest Polytechnical University, Xi'an, 710072, China \\ aemail: zhangxb.no1@163.com \\ bemail: chych888@nwpu.edu.cn \\ cemail: xiuquan_huang@nwpu.edu.cn
}

Keywords: Blade Flutter; Fluid-Structure Interaction(FSI); Aeroelastic Stability; High-low Altitude

\begin{abstract}
Fluid-structure coupled method has been applied to research the aeroelastic stability of compressor blades, and the effects of high-low altitude on blade flutter characteristics are investigated through comparison. Results show that, these frequencies corresponding to displacement, elastic strain of blade are identical with the first order natural frequency based on frequency spectrum analysis, which means that there remains a strong possibility on the frequency in the event of blade flutter. The amplitude of displacement, elastic strain on the ground is greater than that in high altitude, so aeroelastic stability on the ground is lower than that in high altitude.
\end{abstract}

\section{Introduction}

With aerodynamic design system of turbomachinery gradually improving, performance and load of compressor are continually increasing[1],so that the blades have to work in higher aerodynamic and centrifugal load environment. At the same time, to achieve the demand of weight reduction, blades are designed lighter and thinner, which makes the probability of blades flutter higher and higher. This brings a huge challenge to development of compressors for the designers[2].

As the core unit of aero-engine, compressors do not only work in design condition but also in various atmospheric environment of different altitudes. When aircrafts navigate in any given altitude above the sea level, the compressors guarantee itself working in generic characteristic line according to the dynamic similarity relation, yet the similarity rule of aerodynamic performance does not meet that of aeroelastic stability. So the research on the influence of working altitudes on aeroelastic stability of the compressor blade has a prominent value of engineering application.

\section{Numerical method}

To research the blade response in the unsteady flow, structural dynamics equation and fluid mechanics equation must resort to coupled solution[3][4][5]. Through two-way coupling, the aeroelastic characteristic of blades is numerical analyzed. The two-way coupling simulation is achieved by unsteady flow field simulation with CFX, structural dynamic calculation with ANSYS and data exchange between fluid domain and solid domain in the coupling platform is completed by Workbench[6]. The whole computing framework integrates CFD and CSD computation modules.

\section{Numerical simulation and result analysis}

This article selects NASA Rotor67as the research object and applies modal analysis and two-ways fluid structure simulation for the blades.

The blades are modeled by UG software and mesh generation used for structure and flow calculation is accomplished by Design Modeler tool of Workbench and Autogrid5 respectively. The number of elements in the structure domain is 4446, in the flow domain is 178704 . 


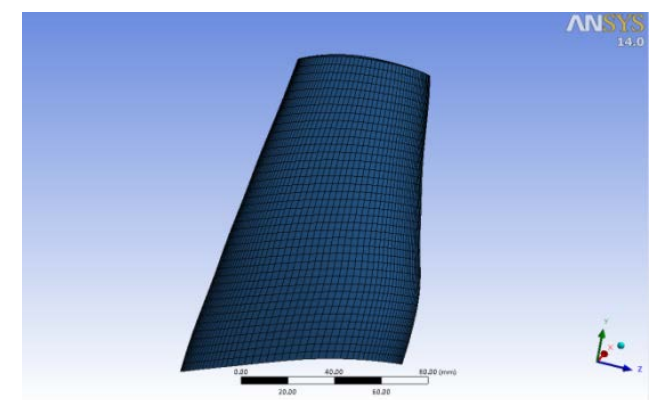

Fig.1 The CSD mesh on the blade surface

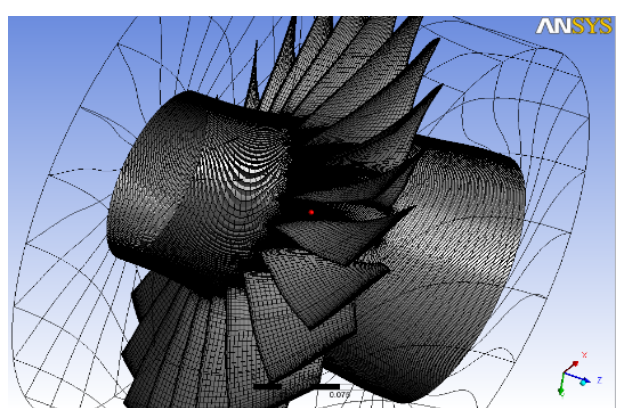

Fig2.The CFD mesh on the blade surface

\section{Modal analysis}

To acquire the vibration modes and natural frequencies of the blade, NASA Rotor67 is processed with modal analysis. Titanium alloyis selected as the material, whose elasticity modulus $E=200 G$ pa, density $\rho=4539 \mathrm{~kg} / \mathrm{m}^{3}$, Poisson's ratio $\sigma=0.3$. The vibration modes and natural frequencies corresponding to the first four modes could be worked out by finite element method. These dynamic frequencies considering blade rotation effect are showed in the Table 1.

Table 1 The first four order natural frequency

\begin{tabular}{cc}
\hline Modal order & Frequency(Hz) \\
\hline 1 & 817.4 \\
\hline 2 & 2208.5 \\
\hline 3 & 3730.1 \\
\hline 4 & 5055.4 \\
\hline
\end{tabular}

According to Fig.3, the first vibration mode is first order bending $(1 \mathrm{~F})$, the second mode is second order bending mode, and the third order mode is first order torsion mode. The positions of the biggest deformation are all at the tip of the blades. However, the fourth order mode is comparatively complicated, not only a pure bending or torsion any more, and the position of the biggest deformation is different from the first three modal as well.

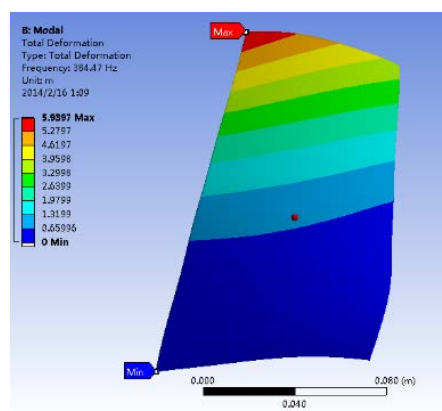

(a) The first mode

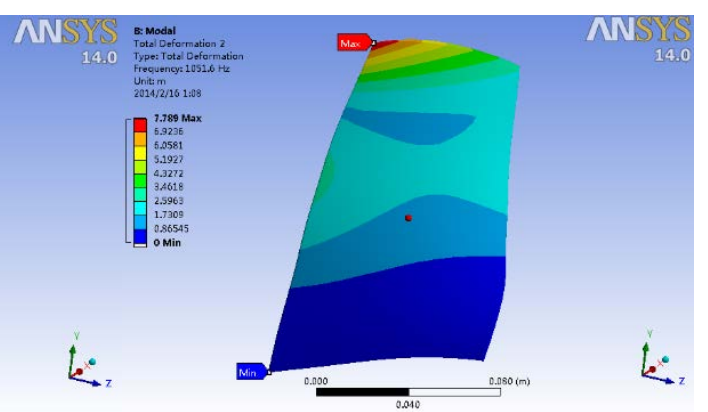

(b) The second mode

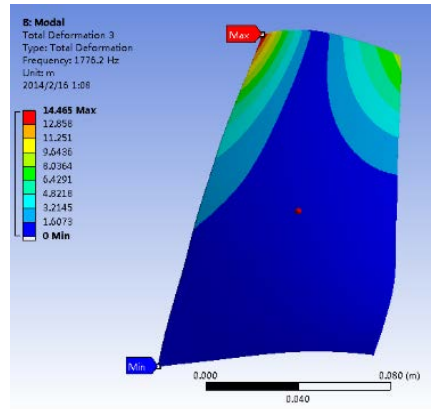

(c) The third mode

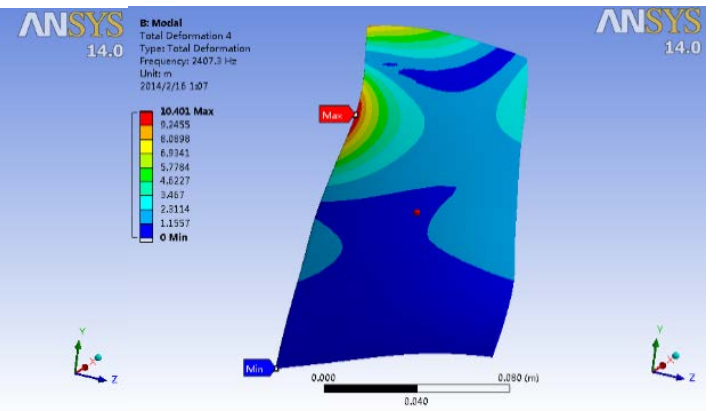

(d) The fourth mode

Fig3.The first four modes of NASA Rotor 67 


\section{Coupling calculation}

NASA Rotor 67 is analyzed by two-way fluid-structure interaction in the two kind of operating altitudes, so as to research the dynamic response in unsteady flow field and the flutter characteristics for the blades in different aerodynamic conditions. Table 2 shows the working conditions corresponding different altitudes for this objective blades. Coupling calculation analysis is done for the blade on the near stall point at the designed rotate speed.

Table 2 The blades working conditions in the different altitudes

\begin{tabular}{cccc}
\hline $\begin{array}{c}\text { Operational } \\
\text { altitude }\end{array}$ & $\begin{array}{c}\text { Inlet total } \\
\text { pressure(Pa) }\end{array}$ & $\begin{array}{c}\text { Inlet total } \\
\text { temperature(K) }\end{array}$ & $\begin{array}{c}\text { Rotation } \\
\text { speed(r/min) }\end{array}$ \\
\hline ground & 101325.0 & 288.15 & 16042 \\
\hline $\begin{array}{c}\text { 8000meter above } \\
\text { sea level }\end{array}$ & 35652.0 & 236.20 & 14529 \\
\hline
\end{tabular}

In order to acquire the time-varying data of displacement on the blade surface, monitors were set on the root, middle, and tip of the blade respectively. The local mesh displacement change sversus time were recorded.

The calculation results of aeroelasticity and unsteady flow response of the Rotor 67 blade are acquired by fluid-solid coupled simulation on the ground and in high altitude. Fig.4(a,b) shows the time-varying displacement on the biggest deformation position in the CFD mesh on the ground and in high altitude respectively. It can be seen that there is a large amplitude vibration in the initial of operation, while the amplitudes of blade vibration gradually decrease with time going on. So blade can keep stable in the two different working conditions.

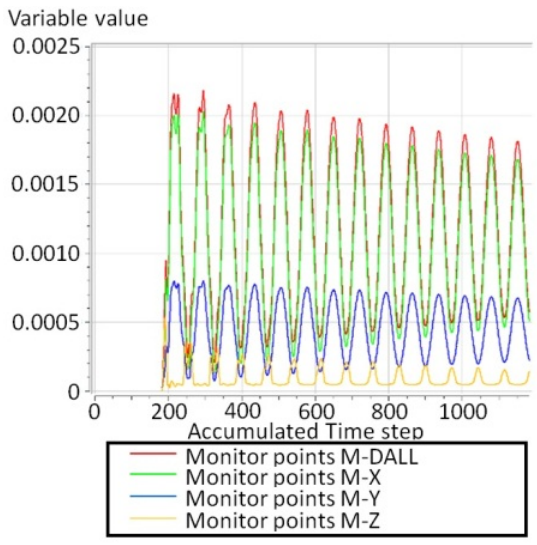

(a) on the ground

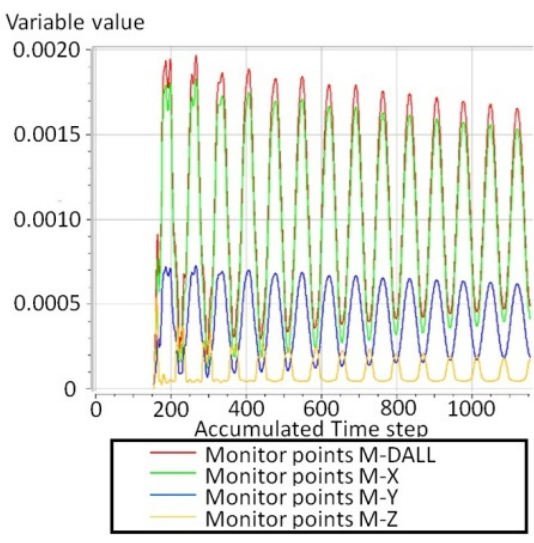

(b) in high altitude

Fig. 4: The displacement changes at the biggest deformation position

Fig.5, 6show the frequency spectral analysis results for blade displacement on the biggest deformation position and elastic strain on the top of the blade respectively. Both displacement and elastic strain have a large amplitude at around $820 \mathrm{~Hz}$, and being compared with the results of modal analysis it is close to the first order modal frequency regardless of ground or high altitude. However, the amplitude of displacement on the ground is greater than that in high altitude, and the amplitude of elastic stain shares the same phenomenon as displacement in high-low altitudes. It means that there is a greater risk on the ground than in high altitude. 


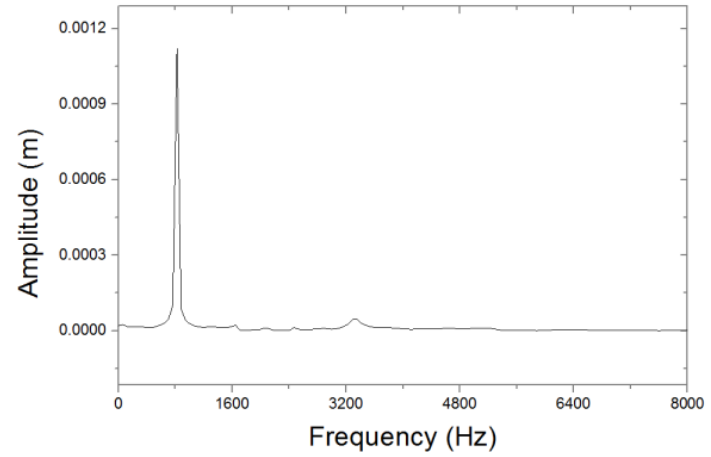

(a) on the ground

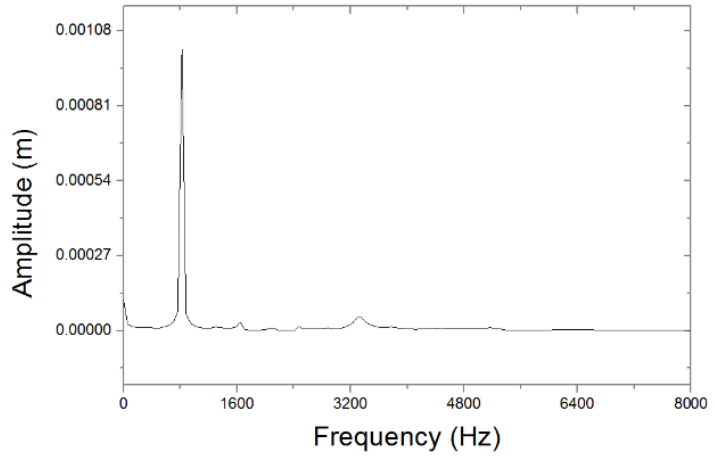

(b) in high altitude

Fig. 5: The frequency spectrum analysis of displacement

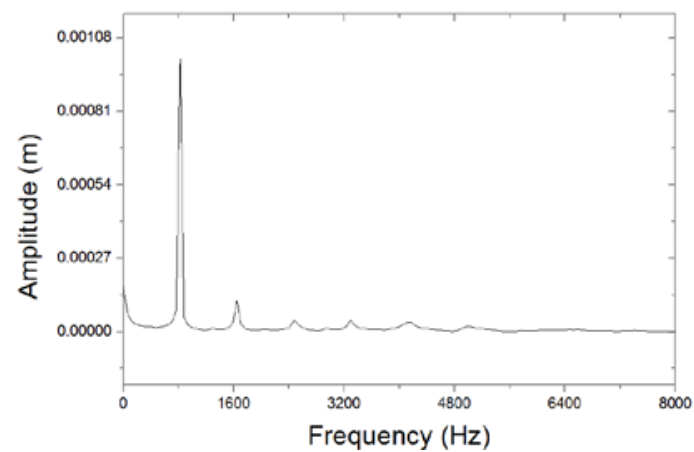

(a) on the ground

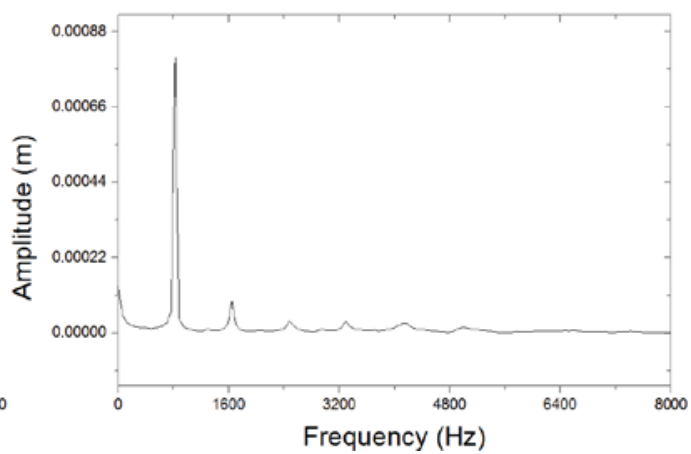

(b) in high altitude

Fig. 6: The frequency spectrum analysis of the elastic strain

\section{Conclusions}

The aeroelastic stability of the NASA Rotor 67 blade in high-low altitude has been analyzed by coupling calculation. The following conclusion can be drawn from the present study:

(1) The vibration displacement of the NASA Rotor 67 gradually decreases versus time,so this blade aeroelasticity is stable regardless of ground and high altitude.

(2) Through frequency spectral analysis of surface displacement and elastic stain in high-low altitude, a corollary that if the blade occurs aeroelastic instability, the vibration frequency would likely be equal with the first order modal frequency.

(3) Blades working on the ground are more likely to flutter than that in high altitude.

\section{Reference}

[1] Isomura K, Giles M. B, A Numerical Study of flutter in a Transonic Fan. ASME Journal of Turbomachinery, 1998, 120(3): 500-507.

[2] Huang Xiuquan, Zhang Xiang, Zhang Hengming. Blade Flutter Prediction Method Based on Hybrid Unsteady/Steady Flow Analysis in a Multi-Stage Environment[J]. Journal of Engineering Thermophysics, 2014,35(7) : 1304-1308(in Chinese).

[3] M Sadeghi, F Liu. Coupled Fluid Structure Simulation for Turbomachinery Blade Rows. AIAA 2005-0018.

[4] Hongsik IM, Xiangying Chen, Gecheng Zha. Detached Eddy Simulation of Transonic Rotor Stall Flutter Using a fully Coupled Fluid-Structure Interaction. ASME GT2011-45437.

[5] Hsu K, Hoyniak D, and M S. Full Annlus Multi-row flutter Analysis. Copenhagen: ASME GT2012-68631.

[6] Zhang Xiaowei, Wang Yanrong, Zhang Xiao and Pei Wei.Numerical method for fluid-structure interaction in turbomachinery bladings. Journal of Aerospace Power, 2009, 24(7): 1622-1666 (in Chinese). 